\title{
ECO, UMBERTO. CONFISSÕES DE UM JOVEM ROMANCISTA. TRADUÇÃO DE CLÓVIS MARQUES. RIO DE JANEIRO: RECORD, 2018, 152 p.
}

\author{
Karine Simoni \\ Universidade Federal de Santa Catarina, Florianópolis, Santa Catarina, Brasil \\ kasimoni@gmail.com
}

O conjunto de quatro ensaios reunidos sob o título de Confissões de um jovem romancista [Confessions of a young novelist], escritos pelo professor, filósofo, semiólogo, crítico literário e romancista Umberto Eco (1932-2016), traduzido ao português por Clóvis Marques e publicado no Brasil em 2018, resultam de reflexões do autor concebidas originalmente como conferências que fizeram parte do programa de palestras Richard Ellmann sobre Literatura Moderna, na Universidade Emory, em Atlanta, Estados Unidos. Nos textos 1. Escrevendo da esquerda para a direita, 2. O autor, o texto e os intérpretes, 3. Algumas observações sobre os personagens fictícios e 4. Minhas listas, Eco discorre sobre a sua experiência como escritor de romances, e caracteriza o próprio livro como obra aberta: "Esta obra em andamento ainda não foi concluída [...], mas espero já ter reunido experiência suficiente para dizer algumas palavras sobre a maneira como escrevo". (p. 07) De início, o título chama a atenção pelo uso do adjetivo "jovem", que é assim explicado pelo autor: "Acontece que publiquei meu primeiro romance, O nome da rosa, em 1980, o que significa que comecei a minha carreira de romancista há apenas 28 anos. Assim, considero-me um romancista muito jovem e certamente promissor, que até agora publicou apenas cinco romances". (p. 07)

Como se percebe, Eco escreve em primeira pessoa e seu texto situa-se no limiar entre apresentação de dados, reflexões filosóficas sobre universos literários, narrativas biográficas, questionamentos e explicações formuladas como afirmações e ou de hipóteses, confissões que dialogam constantemente com o/a leitor/a e o/a instigam a pensar. Resulta uma narrativa marcada por uma linguagem de fácil leitura, mas nem sempre de fácil compreensão devido ao volume de informações, temas, divagações, exemplos retirados de obras literárias de variadas línguas, o que requer um/a leitor/a atento/a e minimamente familiarizado/a com obras, personagens, teorias, reflexões filosóficas, períodos histórico-literários. Por esse motivo, a obra se constitui uma referência que deve interessar principalmente a estudantes e profissionais de Letras e áreas afins.

Embora tenha publicado seu primeiro romance com 48 anos de idade, depois de ter escritos seus textos mais teóricos, Eco remete ao período da infância o seu interesse pela escrita de ficção. Já na primeira página lê-se:

Comecei a escrever romances na infância. A primeira coisa que eu providenciava era o título, em geral inspirado pelos livros de aventuras da época, bem no gênero Piratas do Caribe. Logo desenhava todas as ilustrações, e em seguida iniciava o primeiro capítulo. Mas como eu sempre escrevia em letras maiúsculas, imitando os livros impressos, ficava exausto depois de algumas poucas páginas e desistia. Cada uma das minhas obras era, assim, uma obra-prima inacabada, como a Sinfonia inacabada de Schubert. (p. 07) 
Logo após apresentar esse dado, Eco discute o que pode ser considerado um dos pontos altos do livro: o conceito de "escrita criativa". Para tanto, documenta-se de exemplos do campo literário, filosófico e até da psicologia para questionar: "Nunca entendi por que Homero é considerado um escritor criativo, e Platão, não. Por que um poeta ruim é um escritor criativo, enquanto um bom ensaísta científico não o é? [...] Que tipo de escritor é o filósofo?" (p. 08). Ainda: "Os textos de Galileu certamente são de grande importância filosófica e científica, mas nos colégios de ensino médio italianos são estudados como exemplos de bela escrita criativa." (p. 08). Em sua análise, Eco conclui que a diferença entre escrita científica e escrita criativa está no objetivo de cada escritor. Enquanto no primeiro caso almeja-se comprovar uma tese, ou apresentar respostas a um dado problema, no segundo caso busca-se "representar a vida em toda a sua inconsistência. Queremos evidenciar uma série de contradições, tornando-as evidentes e comoventes. Os escritores criativos pedem que seus leitores experimentem uma solução; não oferecem uma fórmula definitiva.” (p. 10)

Destaco essa reflexão inicial porque ela lança luzes para as etapas seguintes da obra. O título do primeiro ensaio do livro - Escrevendo da esquerda para a direita - representa a explicação de Eco quanto questionado sobre como escrevera seus romances. Em relação a como e porque escreveu $O$ nome da rosa, Eco firma que a ideia surgiu de um convite, feito por uma editora a escritores de não ficção, para que escrevessem um conto policial. Apesar de ter recusado o convite de início, ao encontrar um rascunho onde estavam anotados nomes de monges, surgiu a ideia de envenenar um monge enquanto ele estivesse lendo um livro misterioso, e então estava lançado o início da escrita do romance. O motivo para a escrita é assim resumido: "em determinado momento da vida eu senti essa necessidade - e acho que essa é uma explicação suficiente e razoável.” (p. 11) Talvez o que o autor queira evidenciar respondendo com palavras tão resumidas é a sua crítica aos que desejam explicar a obra literária pela vida do seu autor. Para os críticos que o acusaram de ter usado uma receita mecânica e secreta, um programa de computador, ele responde:

\begin{abstract}
Alimentamos o computador com o conteúdo de cerca de cem romances, trabalhos científicos, a Bíblia, o Corão e um monte de registros telefônicos (muito úteis para os nomes dos personagens). Digamos, algo em torno de 120 mil páginas. Em seguida, [...] misturamos todos os textos, fazendo alguns ajustes [...] (p. 13).
\end{abstract}

Este não é o único momento em que Eco utiliza a ironia e corre o risco de provocar algum riso no/a leitor/a. Neste caso, logo depois ele explica que o fato de ter escrito $O$ nome da rosa em um período considerado breve - dois anos - deu-se porque já possuía conhecimento suficiente sobre o período: "Quando decidi escrever o romance, foi como se tivesse aberto um grande armário onde vinha acumulando meus arquivos medievais por décadas. Todo o material estava ali à minha disposição" (p. 13), o que não ocorreu ao escrever os romances posteriores. Para escrever $O$ pêndulo de Foucault, foram necessários 8 anos; $A$ ilha do dia anterior e Baudolino, 6 anos; A misteriosa chama da Rainha Loana, 4 anos. Eco provavelmente quis destacar, com esses dados, o quão fundamental para a criação das obras é a pesquisa em documentos, visita a lugares, criação de mapas e esboço de personagens, feitos em estado de recolhimento e segredo - "a genialidade é $10 \%$ de inspiração e $90 \%$ de transpiração.” (p. 12) A preparação do texto é para Eco, portanto, uma experiência muito sensorial:

Ao me preparar para escrever $A$ ilha do dia anterior, fui naturalmente aos mares do Sul, à exata localização geográfica em que se passa o romance, para ver as cores da água e do céu em diferentes horas do dia, as tonalidades dos peixes e corais. Mas também passei dois ou três anos estudando desenhos e modelos de navios do período, para descobrir o tamanho de uma cabine ou cubículo e como uma pessoa podia deslocar-se de um para outro. (p. 14) 
O mesmo cuidado afirma ter tido com a elaboração dos outros romances. Tamanho cuidado é explicado pela acepção de que criar uma narrativa é como ser um demiurgo e criar um mundo, o qual deve ser tão preciso quanto possível, para que se possa movimentar-se nele com total confiança.

Além da pesquisa e da experiência corporal com o ambiente no qual será ambientada a narrativa, para iniciar a escrita de um romance, segundo Eco, é fundamental ter uma ideia seminal, que por vezes não passa de uma imagem, como as usadas para escrever $O$ pêndulo de Foucault: a primeira foi o pêndulo de Léon Foucault, visitado 30 anos antes em Paris, e a própria imagem de si tocando trompete no enterro de integrantes da Resistência Italiana - daí a história que se inicia com o pêndulo e termina com um trompetista num cemitério. A resposta sobre como ir de uma imagem à outra foi o romance.

Outra sustentação do autor ao iniciar a escrita de um romance é a definição das palavras a serem utilizadas pelos personagens e pelo narrador, a estrutura dos diálogos, a multiplicidade das línguas e da linguagem. Eco discorre longamente sobre esses aspectos, demonstrando com exemplos e explicações como resolveu as questões de cada romance. $\mathrm{Na}$ sequência, disserta sobre as restrições que, segundo ele, são fundamentais em qualquer empreendimento artístico e que, no caso da escrita de um romance, devem igualmente ser pensadas para que a verossimilhança de fato aconteça. Fazem parte de algumas restrições de seus romances, a título de exemplo: situar a história num momento histórico preciso, no caso d'O nome da rosa; dividir a história d'O pêndulo de Foucault em 10 partes, como as Sefirot da Cabala; manter Baudolino ocupado em um certo trecho do romance para que sua viagem acontecesse exatamente em 1198.

Sem dúvida, a leitura de Confissões de um jovem romancista permite conhecer as entrelinhas do exercício literário, os métodos do autor, nuances do seu pensamento no momento da escrita. Dessa maneira, poderia ser lido também como um paratexto das obras, um exercício (auto)crítico das mesmas.

Antes de encerrar o primeiro ensaio, Eco trata do que ele chama de "dupla decodificação", termo com o qual designa as duas técnicas pós-modernas que usa: a ironia intertextual e o implícito apelo metanarrativo. Dito de outro modo, e utilizando-se da explicação dada pelo arquiteto Charles Jenks, Eco discorre sobre a sensibilidade que o escritor deveria ter para utilizar ao mesmo tempo códigos "cultos" para um público de "elite" e códigos "populares" que sejam compreendidos pelo público de massa. (p. 24) Ao utilizar a técnica de dupla codificação, Eco entende estabelecer uma espécie de

cumplicidade silenciosa com o leitor sofisticado, e alguns leitores populares, quando não alcançam a alusão cultivada, podem sentir que algo lhes escapa. Mas a literatura, acredito, não se destina exclusivamente a entreter e consolar as pessoas. Também tem como objetivo provocar e inspirar as pessoas a lerem o mesmo tempo duas vezes. (p. 25)

No segundo texto, $O$ autor, o texto e os intérpretes, Eco, como o título sugere, discorre sobre as relações entre essas três instâncias e trata da questão das possibilidades de leitura e compreensão de uma obra. Observa que um escritor criativo jamais deve fornecer interpretações da sua própria obra, pois "Um texto é uma máquina preguiçosa que quer que os seus leitores façam parte do seu trabalho.” (p. 28) Por outro lado, o/a leitor/a não pode simplesmente fazer qualquer interpretação, mas deve "certificar-se de que o texto não só legitima como estimula determinada leitura." (p. 28). Nesse ponto, cabe mencionar que o autor defende que por vezes é muito difícil decidir qual interpretação de um texto é a melhor, e, segundo ele, nem sempre essa questão é a mais relevante, mas é sempre possível dizer quando uma interpretação é forçada ou equivocada, uma vez que "Um texto é um dispositivo concebido para gerar seu Leitor Modelo. Esse leitor não é aquele que faz a 'única conjectura 
certa'. Um texto pode prever um Leitor Modelo destinado a experimentar infinitas conjecturas". (p. 31) Reconhecer a intenção do texto é particularmente difícil quando o texto é produzido para mais de um tipo de destinatário, para uma comunidade de leitores. E muitas vezes, os autores "dizem coisas de que não têm consciência; só depois de tomar conhecimento das reações dos leitores é que descobrem o que disseram". (p. 35)

Algumas observações sobre os personagens fictícios é o título do terceiro ensaio e nele Eco se dedica a analisar questões em torno da existência dos personagens dentro e fora do texto: "o cerne da minha reflexão aqui é tentar descobrir por que as pessoas se comovem com personagens fictícios" (p. 54). Em outras palavras, "O que devemos depreender quando as pessoas ficam apenas levemente perturbadas vendo milhões de indivíduos reais morrerem de fome - entre eles muitas crianças -, mas sentem uma profunda aflição pessoal com a morte de Anna Karenina?" (p. 53)

Para elucidar os motivos pelos quais sentimos a dor de uma pessoa que sabemos nunca ter existido, Eco discute conceitos como "verdadeiro", "existência", "indivíduos flutuantes", "objetos semióticos", entre outros, em suas relações com as afirmativas fictícias versus as afirmativas históricas, com a finalidade de levantar hipóteses que contemplem os limites e as interrelações entre a construção do autor e a percepção dos leitores. Inicia seu ensaio com exemplos principalmente de leitores mais ingênuos, pouco familiarizados com as convenções literárias, que ignoram a possibilidade da fantasia do autor e buscam os "objetos reais" descritos em seus romances, mas não deixa de observar também que essa pode ser também uma característica de leitores mais cultos, familiarizados com livros: "o que parece é que muitos leitores, independente de sua condição cultural, são ou se tornam incapazes de distinguir entre ficção e realidade. Levam a sério personagens fictícios, como se fossem seres humanos de verdade". (p. 50) Na tentativa de compreender esse fenômeno, Eco busca respostas em áreas diversas, dialogando seja com a psicologia, seja com a ontologia e com a semiótica. Conclui que o leitor pode se identificar com personagens científicos e suas ações porque começa a viver no mundo possível da narrativa como se fosse o seu próprio mundo real, fenômeno esse que não acontece apenas quando lemos ficção (acontece, por exemplo, quando imaginamos a morte de um ente querido). A capacidade de um personagem despertar emoções no seu leitor depende também dos hábitos culturais desse mesmo leitor, e estes hábitos podem mudar de acordo com a época. Uma das explicações pelas quais um leitor sente o fascínio ou interferência de um dado personagem está no fato, segundo Eco, de que os textos de ficção nunca são ambientados num mundo totalmente diferente daquele em que vivemos, ainda que sejam contos de fada ou textos de ficção científica, pois mesmo nesses casos possuímos referências - por exemplo, "floresta" - que são existentes em nosso mundo real.

Ao discorrer sobre as diferenças entre personagens ficcionais e personagens históricos, Eco destaca:

ninguém pode afirmar todas as propriedades de determinado indivíduo ou determinada espécie, que são potencialmente infinitas, ao passo que as propriedades dos personagens fictícios são severamente limitadas pelo texto narrativo - e só os atributos mencionados no texto contam para a identificação do personagem". (p. 57)

O que o autor parece querer destacar são as diferentes formas de produção de conhecimento, que não se anulam - os historiadores, por exemplo, devem observar, com base em documentos, se determinada informação é relevante ou não para a construção da sua versão da história, e o romancista, que não tem o compromisso com a veracidade históricobiográfica, mas sim com os detalhes que são importantes para a construção dos personagens e para a interpretação da narrativa. O que o leitor deve considerar é que tanto Hitler e Anna Karenina existem, mas são dois tipos de entidades diferentes, situados em contextos variados 
cada qual com seu status ontológico diferente - neste caso, o primeiro foi um ser humano real, enquanto a segunda é um produto da imaginação. Eco, porém, não se abstém de ressaltar o que várias correntes historiográficas têm defendido na pós-modernidade, a saber, que tanto as narrativas fictícias como as históricas são construções que se baseiam em informações textuais, ou seja, "ainda que pareçam expressar verdades de facto, são apenas de dicto". (p. 61) A compreensão e a veracidade dos personagens de ficção passa pelo que o autor chama de legitimidade textual interna, ou seja, a identidade dos personagens é inconfundível, pois não precisamos sair do texto para comprová-la. Um ponto inovador do pensamento de Eco ao tratar essas questões é o que ele intitula "função epistemológica das afirmativas fictícias", ou seja, "as afirmativas fictícias, em virtude da maneira como as usamos e pensamos nelas, são essenciais para esclarecer o nosso conceito de verdade". (p. 63) Dito de outro modo, "uma afirmativa é inquestionavelmente verdadeira quando for tão irrefutável quanto a afirmação ' $\mathrm{O}$ Super-Homem é Clark Kent'.” (p. 63)

Eco também discorre sobre a independência que determinados personagens adquirem para além dos limites de seu ambiente original, e são constantemente retratados e reconduzidos em outras instâncias, como a cinematográfica, ou mesmo tomados como modelos para outra obra ou campo do conhecimento, como Édipo o é para a psicologia, de modo que muitos personagens existem para o imaginário das pessoas mesmo que estas não tenham lido as obras nas quais esses personagens estão inseridos. Esse fenômeno explica por que o personagem fíctício é um objeto semiótico, ou seja, "um conjunto de propriedades registradas na enciclopédia de uma cultura e transmitidas por determinada expressão". Por esse conjunto de características próprias, que aliás deve ser definido para cada personagem fictício, ele pode continuar sendo o mesmo ainda que transportado para uma outra realidade os chamados "personagens flutuantes". Eco cita o conto de Woody Allen, "O episódio Kugelmass", em que Madame Bovary é trazida à Nova York atual por uma espécie de máquina do tempo; embora vista roupas atualizadas, continua fazendo parte da pequena burguesia, casada com um médico, insatisfeita com a sua vida e inclinada ao adultério. Por ser uma entidade flutuantes, um personagem como Madame Bovary - assim como os personagens mitológicos - jamais mudará sua essência e continuará presa aos seus atos, diferentemente de outros objetos semióticos, que podem continuamente estarem sujeitos à revisão. Um personagem histórico pode ter sua biografia modificada a partir da descoberta de informações novas; o que não ocorre no caso de um personagem de ficção, já construído de forma imutável: "E em virtude da inalterabilidade de seus atos, sempre poderemos alegar ser verdade que tinham essas qualidades e se comportavam de determinada maneira" (p. 76), o que, em última instância, serve como um antídoto para interpretações equivocadas.

Eco termina esse ensaio refletindo sobre a força ética dos personagens de ficção:

quando realmente entendemos seu destino, começamos a desconfiar que também
nós, como cidadãos do aqui e agora, muitas vezes vamos ao encontro do nosso
destino porque encaramos o nosso mundo da mesma maneira como os personagens
fictícios encaram o deles. A ficção dá a entender que talvez nossa visão do mundo
real seja tão imperfeita quanto a visão que os personagens fictícios têm do seu
mundo. Por isto é que os personagens fictícios bem-sucedidos tornam-se supremos
exemplos da "real" condição humana.

O último ensaio, intitulado Minhas listas, é talvez o que requeira do leitor maior atenção, dada a quantidade de exemplos e referências que Eco reporta no texto para falar sobre um elemento que lhe é muito estimado na escrita literária: as listas, esse importante artifício que sempre utilizou ao escrever seus romances. Amplamente documentado, o ensaio de Eco revela algumas das numerações pelas quais mais tem afeto, e compara as próprias listas com os catálogos da literatura universal. Inicia apresentando as diferenças entre o que 
ele chama de "listas práticas", como uma lista de compras e ou o catálogo de uma biblioteca, que são listas fechadas, prontas, e as "listas poéticas", abertas, cujo objetivo é "sugerir uma infinidade de pessoas, objetos e acontecimentos, por dois motivos: (1) o escritor tem consciência de que a quantidade de coisas é extensa demais para ser registrada; (2) o escritor sente prazer - às vezes um prazer puramente auditivo - com incessantes numerações.” (p. 82) Ou seja, os escritores costumam fazer listas quando o volume de itens com os quais estão lidando é tão vasta que escapa à sua capacidade de controlá-la. Muitas vezes, menos importa quais nomes estão presentes ou ausentes, e mais o fato de serem enunciados de forma rítmica.

Eco prossegue apresentando ao leitor diferentes tipos de listas, como as acumulações, e dentro destas as enumeratio e as congéries; o incrementum, as anáforas, os assíntetos, entre outras formas. $\mathrm{O}$ autor mantém o leitor atento trazendo, entre definições teóricas, dezenas de exemplos práticos de autores e obras de várias línguas e temporalidades: assim, temos nomes que se utilizaram de listas na literatura greco-latina clássica, no medievo, nas literaturas italiana, espanhola, francesa, inglesa, polonesa, russa, norte-americana, com destaque para uma reflexão sobre o uso e o papel das listas, propositalmente bastante extensas, nos próprios romances $O$ nome da rosa, A ilha do dia anterior, Baudolino, $O$ pêndulo de Foucault, $A$ misteriosa chama da rainha Loana. De todas, Eco é categórico ao afirmar: "O único verdadeiro objetivo de uma boa lista é transmitir a ideia de infinidade e vertigem do et cetera" (p. 86). Veja-se, a título de exemplo, um trecho de $O$ nome da rosa, em que Eco permite-se expandir-se, segundo ele, pelo "puro prazer do som" (p. 90):

\begin{abstract}
Salvatore vagou pelo mundo, mendigando, gatunando, fingindo-se doente, pondo-se ao serviço transitório de algum senhor, tomando novamente o caminho da floresta, da estrada principal. Pela narrativa que me fez pude vê-lo associado aos bandos de vagabundos que depois, nos anos que se seguiram, vi cada vez mais circular pela Europa: falsos monges charlatães, embrulhões, truões esfarrapados e maltrapilhos, leprosos e estropiados, ambulantes, vagabundos, cantadores, clérigos sem pátria, estudantes itinerantes, trapaceiros, malabaristas, mercenários inválidos, judeus errantes, salvos dos infiéis com o espírito destruído, sandeus, fugitivos perseguidos por bandos, malfeitores de orelhas cortadas, sodomitas, e entre eles artesãos ambulantes, tecelões, caldeireiros, cadeireiros, amoladores, empalhadores, pedreiros, e ainda biltres de todo feitio, trapaceiros, birbantes, vigaristas, velhacos, galhofeiros, guiões, alcoviteiros, saltimbancos, andarilhos, esmoleres, e cônegos e padres simoníacos e traficantes, e gente que vivia da credulidade alheia, falsários de bulas e selos papais, vendedores de indulgências, falsos paralíticos que se estendiam às portas das igrejas, trânsfugas dos conventos, vendedores de relíquias, adivinhos e quiromantes, nicromantes, curandeiros, falsos esmoleres, e fornicadores de toda laia, corruptores de monjas e donzelas com enganos e violências, simuladores de hidropisia, epilepsia, hemorroidas, gota e chagas, e mais loucura melancólica. (p. 90)
\end{abstract}

Este não é o único exemplo que o autor destaca e com o qual anuncia o prazer pela enumeração, cuja origem é associada à infância e suas vivências com as ladainhas católicas. Os exemplos de numeração, como foi dito, são bastante numerosos e são retirados tanto da própria obra, como na literatura de várias línguas e nacionalidades.

Este livro, um dos últimos escritos pelo autor, é leitura fundamental para estudantes de Letras e ou profissionais desta área, ou ainda, para os leitores que se interessam em ampliar seus conhecimentos no campo da escrita literária. É possível perceber que algumas reflexões presentes no livro foram retomadas, reformuladas e amadurecidas de outros textos, como de Seis passeios sobre os bosques da ficção (1994), Sobre a literatura (2002) e A vertigem das listas (2009). Nota-se, com a publicação de Confissões de um jovem romancista, que as questões típicas do fazer narrativo continuaram a ocupar o cerne do pensamento de Eco, que continua, sem descuidar da tradição e dos textos que o precederam, a debruçar-se sobre conceitos-chave da escrita criativa, dentre elas a escrita literária. Seu texto, para além do 
objetivo de acolher as confissões do "jovem" romancista, lança também mensagens para o presente e para o futuro daqueles que, a exemplo de Eco, pretendem enveredar pelos caminhos da literatura.

\section{Referências}

Eco, Umberto. Confissões de um jovem romancista. Tradução de Clóvis Marques. Rio de Janeiro: Record, 2018, 152 p.

Recebido em: 30 de agosto de 2019

Aceito em: 17 de outubro de 2019

Publicado em: Dezembro de 2019 